$11-2019$

\title{
Economic Design of Acceptance Sampling Plans for Truncated Life Tests Using Three-Parameter Lindley Distribution
}

Amer Ibrahim Al-Omari

Al al-Bayt University, Mafraq, Jordan, alomari_amer@yahoo.com

Enrico Ciavolino

University of Salento, Lecce, Italy, enrico.ciavolino@unisalento.it

Amjad D. Al-Nasser

Yarmouk University, Irbid, Jordan, amjadyu@yahoo.com

Follow this and additional works at: https://digitalcommons.wayne.edu/jmasm

Part of the Applied Statistics Commons, Social and Behavioral Sciences Commons, and the Statistical Theory Commons

\section{Recommended Citation}

Al-Omari, A. I., Ciavolino, C., \& Al-Nasser, A. D. (2019). Economic design of acceptance sampling plans for truncated life tests using three-parameter Lindley distribution. Journal of Modern Applied Statistical Methods, 18(2), eP2746. doi: 10.22237/jmasm/1604189220

This Regular Article is brought to you for free and open access by the Open Access Journals at DigitalCommons@WayneState. It has been accepted for inclusion in Journal of Modern Applied Statistical Methods by an authorized editor of DigitalCommons@WayneState. 


\section{Economic Design of Acceptance Sampling Plans for Truncated Life Tests Using Three-Parameter Lindley Distribution}

\author{
Amer Ibrahim Al-Omari \\ Al al-Bayt University \\ Mafraq, Jordan
}

\author{
Enrico Ciavolino \\ University of Salento \\ Lecce, Italy
}

\author{
Amjad D. Al-Nasser \\ Yarmouk University \\ Irbid, Jordan
}

A single acceptance sampling plan for the three-parameter Lindley distribution under a truncated life test is developed. For various consumer's confidence levels, acceptance numbers, and values of the ratio of the experimental time to the specified average lifetime, the minimum sample size important to assert a certain average lifetime are calculated. The operating characteristic (OC) function values as well as the associated producer's risks are also provided. A numerical example is presented to illustrate the suggested acceptance sampling plans.

Keywords: Acceptance sampling plan, three-parameter Lindley distribution, operating characteristic function, producer's risk, consumer's risk, truncated life test

\section{Introduction}

Acceptance sampling plan is a quality control decision procedure used when the cost in testing an item is high comparing to the cost of passing a defective item. It is an inspection procedure used by manufacturers, researchers etc., to determine whether to accept or reject a lot based on a pre-specified quality standards. The procedure is considered as a binomial experiment in which the random variable is the number of failures within a pre-determined time. Based on this experiment, the statistical decision is to reject a lot that contains large numbers of items; if the number of failures observed is greater than a specified acceptance number, " $c$ "; otherwise it will be accepted. Drawing decision in this experiment has two risks: from one side, rejection a good lot, known as producer's risk, and acceptance of a bad lot, that known as the consumer's risk. The acceptance sampling plan should

doi: 10.22237/jmasm/1604189220 | Accepted: December 30, 2017; Published: July 28, 2020.

Correspondence: Amer Ibrahim Al-Omari, alomari_amer@yahoo.com 


\section{AL-OMARI ET AL}

be designed such that both types of risks have a minimum value. In order to ensure this, many authors have tested this kind of sampling plans, taking into account different procedures, sampling techniques or distributions.

Aslam, Kundu, and Ahmad (2007), Aslam, Jun, et al. (2011), and Gui and Aslam (2017) developed acceptance sampling plan for a generalized and weighted exponential distribution, respectively. Al-Omari (2015) considered the time truncated acceptance sampling plans using the generalized inverted exponential distribution. Tsai and Wu (2006) suggested a single sampling plan when the life time follows generalized Rayleigh distribution. Al-Omari (2014) suggested a sampling plan for the three-parameter kappa distribution. Al-Omari (2016) for generalized inverse Weibull distribution. Al-Omari et al. (2017) proposed double acceptance sampling plan for exponentiated generalized inverse Rayleigh distribution. Al-Omari and Zamanzade (2017) introduced double acceptance sampling plan transmuted generalized inverse Weibull distribution. Malathi and Muthulakshmi (2017) developed acceptance sampling plans for truncated life test using Frechet distribution. Nehzad and Seifi (2017) proposed repetitive group sampling plan based on the process capability index.

The main aim of this research is to develop acceptance sampling plans for the three-parameter Lindley distribution (Abd El-Monsef, 2016) which is a generalization of the one-parameter Lindley distribution that suggested by Ghitany et al. (2008). To best of our knowledge that is this is the first paper considered an acceptance sampling plan for the three-parameter Lindley distribution.

\section{Three-Parameter Lindley Distribution}

In the context of Bayesian analysis, Lindley (1958) introduced a single parameter distribution and defined its probability density function (pdf) and cumulative distribution function (cdf) as

$$
\begin{aligned}
& \mathrm{f}(z, \theta)=\frac{\theta^{2}}{\theta+1}(1+z) \mathrm{e}^{-\theta z} ; \quad z>0, \theta>0 \\
& \mathrm{~F}(z, \theta)=1-\left(1+\frac{\theta z}{1+\theta}\right) \mathrm{e}^{-\theta z} ; \quad z>0, \theta>0
\end{aligned}
$$

Shanker, Fesshaye, and Sharma (2016) used this distribution for modelling life time data. An extension to Lindley distribution has been made by Shanker and Mishra (2013) by adding another parameter to the distribution and name it by two- 


\section{THREE-PARAMETER LINDLEY DISTRIBUTION IN ASP}

parameter Lindely distribution. Later, Abd El-Monsef (2016) proposed a threeparameter Lindley distribution; which we are interested in this article, and defined its probability density function as

$$
\mathrm{f}_{3 \mathrm{P}-\mathrm{L}}(z ; \theta, \alpha, \beta)=\frac{\theta^{2}}{\theta+\alpha}[1+\alpha(z-\beta)] \mathrm{e}^{-\theta(z-\beta)},
$$

where $z>\beta \geq 0, \theta>0, \alpha>0$, and $\beta$ is a location parameter. The cumulative distribution function corresponding to the pdf given in equation (1) is given by

$$
\mathrm{F}_{3 \mathrm{P}-\mathrm{L}}(z ; \theta, \alpha, \beta)=1-\left[1+\frac{\alpha \theta(z-\beta)}{\theta+\alpha}\right] \mathrm{e}^{-\theta(z-\beta)},
$$

where $z>\beta \geq 0, \theta>0$, and $\alpha>0$.

Figures 1 and 2 show the shape of the pdf and cdf of the three-parameter Lindley distribution.

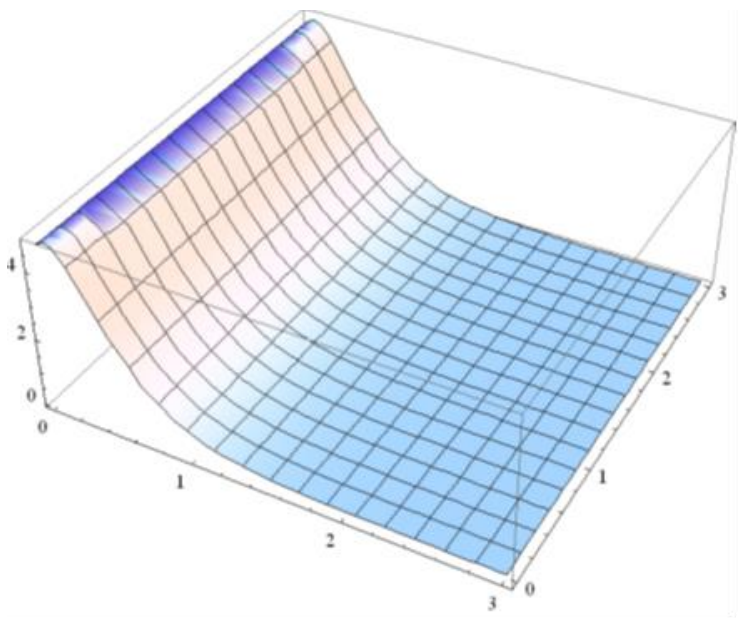

Figure 1. The pdf of the three-parameter Lindley distribution $\alpha=3, \beta=3, \gamma=3, \lambda=-0.9$, with $\theta=3, \beta=0.3$, and $\alpha=0.5$ 


\section{AL-OMARI ET AL}

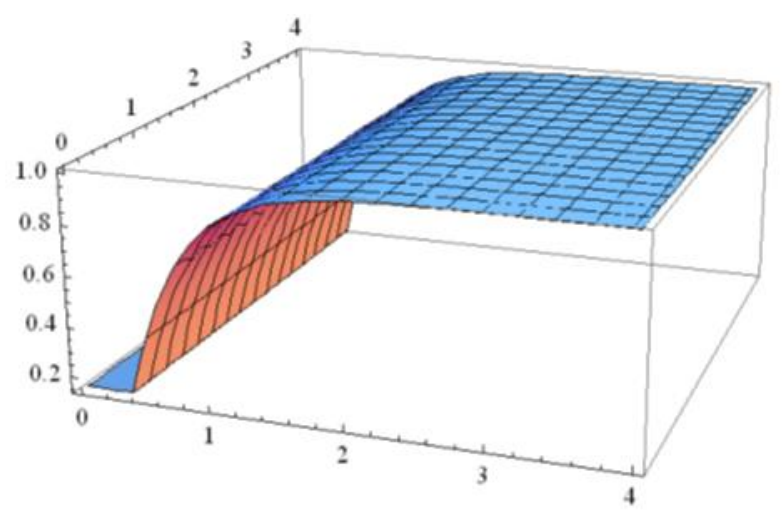

Figure 2. The cdf of the three-parameter Lindley distribution $\alpha=3, \beta=3, \gamma=3, \lambda=-0.9$, with $\theta=3, \beta=0.3$, and $\alpha=0.5$

The quantile function of the three-parameter Lindley distribution is

$$
\mathrm{F}^{-1}(u)=\beta-\left(\frac{\alpha+\theta}{\alpha \theta}\right)-\frac{1}{\theta} \mathrm{W}_{-1}\left[(u-1)\left(\frac{\alpha+\theta}{\alpha}\right) \mathrm{e}^{-\left(\frac{\alpha+\theta}{\alpha}\right)}\right], \quad 0<u<1
$$

where $z>\beta \geq 0, \theta>0, \alpha>0$, and $\mathrm{W}_{-1}$ is the negative branch of the Lambert $\mathrm{W}$ function. The mean of the three-parameter Lindley distribution is given by

$$
\mu_{3 \mathrm{P}-\mathrm{L}}=\mathrm{E}(Z)=\frac{\theta(1+\beta \theta)+\alpha(2+\beta \theta)}{\theta(\alpha+\theta)}
$$

with moment generating function

$$
\mathrm{M}_{z}(t)=\frac{\theta^{2}}{\alpha+\theta}\left[\frac{\mathrm{e}^{t \beta}(\theta+\alpha-t)}{(t-\theta)^{2}}\right]
$$

The survival and hazard functions associated with equation (1), respectively, are given by

$$
\begin{aligned}
\mathrm{S}_{3 \mathrm{P}-\mathrm{L}}(t ; \theta, \alpha, \beta) & =1-\mathrm{F}_{3 \mathrm{P}-\mathrm{L}}(t ; \theta, \alpha, \beta) \\
& =1-\left[1+\frac{\alpha \theta(t-\beta)}{\theta+\alpha}\right] \mathrm{e}^{-\theta(t-\beta)} ; \quad t>\beta
\end{aligned}
$$




\section{THREE-PARAMETER LINDLEY DISTRIBUTION IN ASP}

and

$$
\begin{aligned}
\mathrm{h}_{3 \mathrm{P}-\mathrm{L}}(t ; \theta, \alpha, \beta) & =\frac{\mathrm{f}_{3 \mathrm{P}-\mathrm{L}}(t ; \theta, \alpha, \beta)}{\mathrm{S}_{3 \mathrm{P}-\mathrm{L}}(t ; \theta, \alpha, \beta)} \\
& =\frac{\theta^{2}[1+\alpha(t-\beta)]}{(\alpha+\theta)+\alpha \theta(t-\beta)} ; \quad t>\beta
\end{aligned}
$$

The distribution is unimodal at

$$
z_{0}=\frac{\alpha-\theta+\alpha \theta \beta}{\alpha \theta}, \quad \alpha>0, \quad \text { and } \quad \beta>\frac{\theta-\alpha}{\alpha \theta}
$$

The variance of the distribution is

$$
\sigma_{3 \mathrm{P}-\mathrm{L}}^{2}=\frac{2 \alpha^{2}+4 \alpha \theta+\theta^{2}}{\theta^{3}(\alpha+\theta)^{2}} .
$$

The maximum likelihood estimators of the three-parameter Lindley distribution parameters can be obtained by solving the following equations simultaneously:

$$
\begin{aligned}
-\frac{n}{\theta+\alpha}+\frac{2 n}{\theta}+n(\beta-\bar{z}) & =0 \\
-\frac{n}{\theta+\alpha}+\sum_{i=1}^{n} \frac{z_{i}-\beta}{1+\alpha\left(z_{i}-\beta\right)} & =0 \\
-n \theta+\sum_{i=1}^{n} \frac{\alpha}{1+\alpha\left(z_{i}-\beta\right)} & =0
\end{aligned}
$$

Other properties of the three-parameter Lindley distribution can be found in Abd El-Monsef (2016). It worth to say, a different three-parameter Lindley distribution is proposed by Shanker, Kumar, et al. (2017). 


\section{AL-OMARI ET AL}

\section{Design of the Acceptance Sampling Plan}

Assume the life time of the submitted products follows a three-parameter Lindley distribution given in equation (1). An acceptance sampling plan based on truncated life tests consists of:

(1) The number of units $n$ to be drawn from the lot.

(2) An acceptance number $c$, where if at most $c$ failures out of $n$ occur at the end of the pre-determined time $t_{0}$, the lot is accepted.

(3) The ratio $t_{0} / \mu_{0}$, where $\mu_{0}$ is the specified mean (quality parameter) life and $t_{0}$ is the maximum test duration.

\section{Minimum Sample Size}

The size of the lot is assumed to be very large (to be considered infinite) so that the binomial distribution can be applied. Assume the consumer's risk is determined to be at most $1-P^{*}$, i.e., the probability that the real mean life $\mu$ is less than $\mu_{0}$, does not exceed $1-P^{*}$. The probability of acceptance a lot is calculated using the inequality

$$
\sum_{w=0}^{c}\left(\begin{array}{l}
n \\
w
\end{array}\right) p^{w}(1-p)^{n-w} \leq 1-P^{*},
$$

where $P^{*} \in(0,1)$ and

$$
p=\mathrm{F}\left(t ; \mu_{0}\right)=1-\left[1+\frac{\alpha \theta\left(t_{0}-\beta\right)}{\theta+\alpha}\right] \mathrm{e}^{-\theta\left(t_{0}-\beta\right)}
$$

is the probability of a failure observed within the time $t$ which depends only on the ratio $t / \mu_{0}$.

If the number of observed failures within the time $t$ is at most $c$, then from equation (8) conclude $\mathrm{P}\left[\mathrm{F}(t ; \mu) \leq \mathrm{F}\left(t ; \mu_{0}\right)\right]=P^{*}$ if and only if $\mathrm{P}\left(\mu_{0} \leq \mu\right)=P^{*}$. The rejection or acceptance of the lot are equivalent to the rejection or acceptance of the hypothesis $\mathrm{H}_{0}: \mu_{0} \leq \mu$.

The minimum values of $n$ in equation (8) are calculated for $t / \mu_{0}=0.628$, $0.942,1.257,1.571,2.356,3.141,3.927$, and 4.712 , and the values of $P^{*}$ are 0.75 , $0.90,0.95$, and 0.99 . The selection of these values of $t / \mu_{0}$ and $P^{*}$ are to compare our results with corresponding values given in Gupta and Groll (1961), Baklizi and 


\section{THREE-PARAMETER LINDLEY DISTRIBUTION IN ASP}

El Masri (2004), Kantam et al. (2001), and Al-Nasser and Al-Omari (2013). The smallest sample sizes satisfying inequality (8) for $t / \mu_{0}, P^{*}$, and $\mathrm{c}=0,1,2, \ldots, 10$ for the parameters $\beta=0.9, \alpha=25$, and $\theta=0.1$ are presented in Table 1 .

\section{Operating Characteristic Function}

The operating characteristic function of the sampling plan $\left(n, c, t / \mu_{0}\right)$ gives the probability of accepting the lot. For truncated acceptance sampling plan the probability is given by

$$
\mathrm{L}(p)=\sum_{x=w}^{c}\left(\begin{array}{l}
n \\
w
\end{array}\right) p^{w}(1-p)^{n-w}
$$

where $p=\mathrm{F}(t ; \mu)$ is considered as a function of the mean $\mu$. The operating characteristic function values as a function of $\mu \geq \mu_{0}$ for the sampling plan $\left(n, c=2, t / \mu_{0}\right)$ are given in Table 2 for $\beta=0.9, \alpha=25$, and $\theta=0.1$ in the threeparameter Lindley distribution. At fixed time $t$, the operating characteristic is a decreasing function in the probability $\mathrm{P}$, while $\mathrm{P}$ itself is a monotonically decreasing function of $\mu \geq \mu_{0}$. The choice of $c$ and $n$ can be based on the operation characteristic function for a given $P^{*} \in(0,1)$ and $t / \mu_{0}$.

\section{Producer's Risk}

The producer's risk (PR) is the probability of rejecting the lot when $\mu \geq \mu_{0}$. For a given value of the producer's risk, say $\varepsilon$, a researcher may be interested in knowing the value of $\mu / \mu_{0}$ which will assert the producer's risk to be at most $\varepsilon$. Therefore, $\mu / \mu_{0}$ is the smallest positive number for which $p=\mathrm{F}\left(\frac{t}{\mu_{0}} ; \frac{\mu_{0}}{\mu}\right)$ satisfies the inequality

$$
\sum_{w=0}^{n}\left(\begin{array}{l}
n \\
w
\end{array}\right) p^{w}(1-p)^{n-w} \geq 1-\varepsilon .
$$

For a given acceptance sampling plan $\left(n, c, t / \mu_{0}\right)$, at a determined confidence level $P^{*}$, the minimum values of $\mu / \mu_{0}$ satisfying inequality (9) are obtained and given in Table 3 for $\beta=0.9, \alpha=25$, and $\theta=0.1$ in the three-parameter Lindley distribution. 


\section{AL-OMARI ET AL}

\section{Descriptions of Tables}

Assume the life time of a product follows a three-parameter Lindley distribution. Let $T \sim \mathrm{f}_{3 \mathrm{P}-\mathrm{L}}(z ; \theta, \alpha, \beta)$ with $\beta=0.9, \alpha=25$, and $\theta=0.1$. Assume that the researcher wants to establish that the true unknown mean life is at least 1000 hours $\left(\mu_{0}\right)$ with confidence level $P^{*}=0$, and that the life test will be terminated at $t=628$ hours. Therefore, for an acceptance number $c=2$, the required sample size $n$ is obtained in Table 1 to be 15. That is, if within 628 hours no more than 15 failures are observed, then the researcher can confirm with confidence 0.90 that the mean life is at least 1000 .

For the sampling plan $\left(n=15, c=2, t / \mu_{0}=0.628\right)$, the operating characteristic values from Table 2 are

$\begin{array}{rrrrrrr}\mu / \mu_{0} & 2 & 4 & 6 & 8 & 10 & 12 \\ \text { OC } & 0.803512 & 0.995847 & 0.999854 & 0.999994 & 1 & 1\end{array}$

This means that if the mean life is twice the specified average life $\left(\mu / \mu_{0}=2\right)$ then the producer's risk is 0.196488 , while the producer's risk is about zero for $\mu / \mu_{0} \geq 6$.

Table 3 can be used to find the value of $\mu / \mu_{0}$ for various choices of $t / \mu_{0}$ and $c$ such that the producer's risk may not exceed 0.05 . As an example, the value of $\mu / \mu_{0}$ is 3.4 for $c=2, t / \mu_{0}=0.628$, and $P^{*}=0.9$. This indicates the product must have a mean life of 3.4 times the specified mean life in order to accept the lot with probability 0.90 .

Table 1. Minimum sample size to assert that the mean life exceeds a given value $\mu_{0}$ with probability $P^{*}$ and acceptance number $c$ based on binomial probabilities when $\beta=0.9$, $\alpha=25$, and $\theta=0.1$

\begin{tabular}{rrrrrrrrrr} 
& \multicolumn{10}{c}{$\boldsymbol{t} / \boldsymbol{\mu}_{\mathbf{0}}$} \\
\cline { 3 - 10 } $\boldsymbol{P}^{*}$ & $\mathbf{0 . 6 2 8}$ & $\mathbf{0 . 9 4 2}$ & $\mathbf{1 . 2 5 7}$ & $\mathbf{1 . 5 7 1}$ & $\mathbf{2 . 3 5 6}$ & $\mathbf{3 . 1 4 1}$ & $\mathbf{3 . 9 2 7}$ & $\mathbf{4 . 7 1 2}$ \\
\hline 0.75 & 0 & 13 & 6 & 4 & 3 & 2 & 1 & 1 & 1 \\
0.75 & 1 & 26 & 12 & 8 & 6 & 4 & 3 & 2 & 2 \\
0.75 & 2 & 38 & 18 & 11 & 8 & 5 & 4 & 4 & 3 \\
0.75 & 3 & 49 & 24 & 15 & 11 & 7 & 5 & 5 & 4 \\
0.75 & 4 & 60 & 29 & 18 & 14 & 9 & 7 & 6 & 5 \\
0.75 & 5 & 71 & 34 & 22 & 16 & 10 & 8 & 7 & 7 \\
0.75 & 6 & 82 & 40 & 25 & 19 & 12 & 9 & 8 & 8 \\
0.75 & 7 & 93 & 45 & 29 & 21 & 14 & 11 & 9 & 9 \\
0.75 & 8 & 104 & 50 & 32 & 24 & 15 & 12 & 11 & 10 \\
0.75 & 9 & 114 & 55 & 35 & 26 & 17 & 13 & 12 & 11 \\
0.75 & 10 & 125 & 60 & 39 & 29 & 18 & 15 & 13 & 12 \\
\hline
\end{tabular}


Table 1 (continued).

\begin{tabular}{|c|c|c|c|c|c|c|c|c|c|}
\hline \multirow[b]{2}{*}{$\boldsymbol{P}^{*}$} & \multirow[b]{2}{*}{$c$} & \multicolumn{8}{|c|}{$t / \mu_{0}$} \\
\hline & & 0.628 & 0.942 & 1.257 & 1.571 & 2.356 & 3.141 & 3.927 & 4.712 \\
\hline 0.90 & 0 & 6 & 3 & 2 & 2 & 1 & 1 & 1 & 1 \\
\hline 0.90 & 1 & 11 & 6 & 4 & 3 & 3 & 2 & 2 & 2 \\
\hline 0.90 & 2 & 15 & 9 & 6 & 5 & 4 & 3 & 3 & 3 \\
\hline 0.90 & 3 & 19 & 11 & 8 & 6 & 5 & 4 & 4 & 4 \\
\hline 0.90 & 4 & 23 & 13 & 10 & 8 & 6 & 5 & 5 & 5 \\
\hline 0.90 & 5 & 27 & 15 & 11 & 9 & 7 & 6 & 6 & 6 \\
\hline 0.90 & 6 & 30 & 18 & 13 & 11 & 8 & 7 & 7 & 7 \\
\hline 0.90 & 7 & 34 & 20 & 14 & 12 & 9 & 9 & 8 & 8 \\
\hline 0.90 & 8 & 38 & 22 & 16 & 13 & 11 & 10 & 9 & 9 \\
\hline 0.90 & 9 & 41 & 24 & 18 & 15 & 12 & 11 & 10 & 10 \\
\hline 0.90 & 10 & 45 & 26 & 19 & 16 & 13 & 12 & 11 & 11 \\
\hline 0.95 & 0 & 4 & 3 & 2 & 2 & 1 & 1 & 1 & 1 \\
\hline 0.95 & 1 & 7 & 4 & 3 & 3 & 2 & 2 & 2 & 2 \\
\hline 0.95 & 2 & 10 & 6 & 5 & 4 & 3 & 3 & 3 & 3 \\
\hline 0.95 & 3 & 12 & 8 & 6 & 5 & 4 & 4 & 4 & 4 \\
\hline 0.95 & 4 & 15 & 9 & 7 & 6 & 5 & 5 & 5 & 5 \\
\hline 0.95 & 5 & 17 & 11 & 9 & 8 & 6 & 6 & 6 & 6 \\
\hline 0.95 & 6 & 19 & 12 & 10 & 9 & 8 & 7 & 7 & 7 \\
\hline 0.95 & 7 & 21 & 14 & 11 & 10 & 9 & 8 & 8 & 8 \\
\hline 0.95 & 8 & 24 & 15 & 12 & 11 & 10 & 9 & 9 & 9 \\
\hline 0.95 & 9 & 26 & 17 & 14 & 12 & 11 & 10 & 10 & 10 \\
\hline 0.95 & 10 & 28 & 18 & 15 & 13 & 12 & 11 & 11 & 11 \\
\hline 0.99 & 0 & 4 & 3 & 2 & 2 & 1 & 1 & 1 & 1 \\
\hline 0.99 & 1 & 7 & 4 & 3 & 3 & 2 & 2 & 2 & 2 \\
\hline 0.99 & 2 & 9 & 6 & 5 & 4 & 3 & 3 & 3 & 3 \\
\hline 0.99 & 3 & 11 & 7 & 6 & 5 & 4 & 4 & 4 & 4 \\
\hline 0.99 & 4 & 13 & 8 & 7 & 6 & 5 & 5 & 5 & 5 \\
\hline 0.99 & 5 & 14 & 10 & 8 & 7 & 6 & 6 & 6 & 6 \\
\hline 0.99 & 6 & 16 & 11 & 9 & 8 & 7 & 7 & 7 & 7 \\
\hline 0.99 & 7 & 18 & 12 & 10 & 9 & 8 & 8 & 8 & 8 \\
\hline 0.99 & 8 & 20 & 14 & 11 & 10 & 9 & 9 & 9 & 9 \\
\hline 0.99 & 9 & 21 & 15 & 13 & 12 & 10 & 10 & 10 & 10 \\
\hline 0.99 & 10 & 23 & 16 & 14 & 13 & 11 & 11 & 11 & 11 \\
\hline
\end{tabular}




\section{AL-OMARI ET AL}

Table 2. Operating characteristic function values for the sampling plan $\left(n, c=2, t / \mu_{0}\right)$ for a given probability $P^{\prime}$ with $\beta=0.9, \alpha=25$, and $\theta=0.1$

\begin{tabular}{|c|c|c|c|c|c|c|c|c|}
\hline \multirow[b]{2}{*}{$P^{*}$} & \multirow[b]{2}{*}{$n$} & \multirow[b]{2}{*}{$t / \mu_{0}$} & \multicolumn{6}{|c|}{$\boldsymbol{\mu} / \boldsymbol{\mu}_{0}$} \\
\hline & & & 2 & 4 & 6 & 8 & 10 & 12 \\
\hline 0.75 & 38 & 0.628 & 0.947240 & 0.999891 & 1 & 1 & 1 & 1 \\
\hline 0.75 & 18 & 0.942 & 0.918498 & 0.999247 & 0.999989 & 1 & 1 & 1 \\
\hline 0.75 & 11 & 1.257 & 0.903173 & 0.998380 & 0.999945 & 0.999998 & 1 & 1 \\
\hline 0.75 & 8 & 1.571 & 0.885158 & 0.997250 & 0.999862 & 0.999990 & 0.999999 & 1 \\
\hline 0.75 & 5 & 2.356 & 0.839510 & 0.993433 & 0.999465 & 0.999934 & 0.999990 & 0.999998 \\
\hline 0.75 & 4 & 3.141 & 0.775634 & 0.986705 & 0.998595 & 0.999780 & 0.999956 & 0.999990 \\
\hline 0.75 & 4 & 3.927 & 0.592870 & 0.961674 & 0.994901 & 0.999054 & 0.999780 & 0.999940 \\
\hline 0.75 & 3 & 4.712 & 0.709664 & 0.973527 & 0.996235 & 0.999244 & 0.999809 & 0.999943 \\
\hline 0.90 & 15 & 0.628 & 0.803512 & 0.995847 & 0.999854 & 0.999994 & 1 & 1 \\
\hline 0.90 & 9 & 0.942 & 0.707525 & 0.987677 & 0.999152 & 0.999917 & 0.999990 & 0.999999 \\
\hline 0.90 & 6 & 1.257 & 0.693104 & 0.982645 & 0.998404 & 0.999786 & 0.999964 & 0.999993 \\
\hline 0.90 & 5 & 1.571 & 0.616632 & 0.970560 & 0.996670 & 0.999464 & 0.999892 & 0.999975 \\
\hline 0.90 & 4 & 2.356 & 0.415407 & 0.917778 & 0.986698 & 0.997182 & 0.999268 & 0.999780 \\
\hline 0.90 & 3 & 3.141 & 0.470690 & 0.916564 & 0.984395 & 0.996237 & 0.998899 & 0.999629 \\
\hline 0.90 & 3 & 3.927 & 0.280550 & 0.824554 & 0.958699 & 0.988464 & 0.996234 & 0.998609 \\
\hline 0.90 & 3 & 4.712 & 0.156361 & 0.709664 & 0.916532 & 0.973527 & 0.990525 & 0.996235 \\
\hline 0.95 & 10 & 0.628 & 0.642997 & 0.983142 & 0.998809 & 0.999882 & 0.999986 & 0.999998 \\
\hline 0.95 & 6 & 0.942 & 0.580140 & 0.968492 & 0.996656 & 0.999499 & 0.999906 & 0.999980 \\
\hline 0.95 & 5 & 1.257 & 0.430858 & 0.932675 & 0.990602 & 0.998244 & 0.999594 & 0.999891 \\
\hline 0.95 & 4 & 1.571 & 0.415199 & 0.917710 & 0.986683 & 0.997178 & 0.999267 & 0.999779 \\
\hline 0.95 & 3 & 2.356 & 0.367241 & 0.874379 & 0.973527 & 0.993108 & 0.997864 & 0.999244 \\
\hline 0.95 & 3 & 3.141 & 0.156422 & 0.709741 & 0.916564 & 0.973539 & 0.990530 & 0.996237 \\
\hline 0.95 & 3 & 3.927 & 0.060273 & 0.527602 & 0.824554 & 0.934288 & 0.973517 & 0.988464 \\
\hline 0.95 & 3 & 4.712 & 0.022068 & 0.367241 & 0.709664 & 0.874379 & 0.943854 & 0.973527 \\
\hline 0.99 & 9 & 0.628 & 0.394149 & 0.9 & 0.993970 & 0.999152 & 0.999855 & 0.999972 \\
\hline 0.99 & 6 & 0.942 & 0.277930 & 0.886543 & 0.982717 & 0.996656 & 0.999214 & 0.999788 \\
\hline 0.99 & 5 & 1.257 & 0.166265 & 0.799617 & 0.960075 & 0.990602 & 0.997390 & 0.999175 \\
\hline 0.99 & 4 & 1.571 & 0.167046 & 0.775417 & 0.949211 & 0.986683 & 0.995931 & 0.998592 \\
\hline 0.99 & 3 & 2.356 & 0.156361 & 0.709664 & 0.916532 & 0.973527 & 0.990525 & 0.996235 \\
\hline 0.99 & 3 & 3.141 & 0.043345 & 0.470690 & 0.788129 & 0.916564 & 0.965148 & 0.984395 \\
\hline 0.99 & 3 & 3.927 & 0.011087 & 0.280550 & 0.627988 & 0.824554 & 0.916507 & 0.958699 \\
\hline 0.99 & 3 & 4.712 & 0.002727 & 0.156361 & 0.470596 & 0.709664 & 0.845317 & 0.916532 \\
\hline
\end{tabular}




\section{THREE-PARAMETER LINDLEY DISTRIBUTION IN ASP}

Table 3. Minimum ratio of the true mean life to specified mean life for the acceptance of a lot with producer's risk of 0.05 with $\beta=0.9, \alpha=25$, and $\theta=0.1$

\begin{tabular}{|c|c|c|c|c|c|c|c|c|c|}
\hline \multirow[b]{2}{*}{$P$} & \multirow[b]{2}{*}{ C } & \multicolumn{8}{|c|}{$t / \mu_{0}$} \\
\hline & & 0.628 & 0.942 & 1.257 & 1.571 & 2.356 & 3.141 & 3.927 & 4.712 \\
\hline 0.75 & 0 & 3.537 & 4.233 & 4.933 & 5.561 & 7.141 & 7.117 & 8.897 & 10.676 \\
\hline 0.75 & 1 & 2.393 & 2.648 & 2.946 & 3.201 & 3.862 & 4.325 & 4.027 & 4.832 \\
\hline 0.75 & 2 & 2.018 & 2.195 & 2.295 & 2.407 & 2.676 & 3.011 & 3.764 & 3.433 \\
\hline 0.75 & 3 & 1.818 & 1.978 & 2.071 & 2.166 & 2.405 & 2.416 & 3.020 & 2.807 \\
\hline 0.75 & 4 & 1.698 & 1.817 & 1.879 & 2.022 & 2.242 & 2.423 & 2.592 & 2.446 \\
\hline 0.75 & 5 & 1.618 & 1.710 & 1.800 & 1.852 & 1.975 & 2.147 & 2.312 & 2.774 \\
\hline 0.75 & 6 & 1.559 & 1.656 & 1.703 & 1.794 & 1.924 & 1.951 & 2.112 & 2.534 \\
\hline 0.75 & 7 & 1.515 & 1.595 & 1.664 & 1.697 & 1.882 & 2.006 & 1.962 & 2.354 \\
\hline 0.75 & 8 & 1.479 & 1.547 & 1.603 & 1.668 & 1.749 & 1.872 & 2.110 & 2.212 \\
\hline 0.75 & 9 & 1.445 & 1.509 & 1.554 & 1.602 & 1.733 & 1.764 & 1.993 & 2.098 \\
\hline 0.75 & 10 & 1.422 & 1.477 & 1.537 & 1.586 & 1.637 & 1.816 & 1.897 & 2.004 \\
\hline 0.90 & 0 & 5.643 & 6.669 & 7.620 & 9.524 & 10.676 & 14.233 & 17.794 & 21.351 \\
\hline 0.90 & 1 & 3.400 & 3.839 & 4.121 & 4.326 & 6.488 & 6.441 & 8.053 & 9.663 \\
\hline 0.90 & 2 & 2.683 & 3.086 & 3.230 & 3.569 & 4.516 & 4.577 & 5.723 & 6.866 \\
\hline 0.90 & 3 & 2.346 & 2.597 & 2.823 & 2.843 & 3.624 & 3.742 & 4.678 & 5.613 \\
\hline 0.90 & 4 & 2.149 & 2.314 & 2.587 & 2.723 & 3.110 & 3.260 & 4.076 & 4.891 \\
\hline 0.90 & 5 & 2.018 & 2.129 & 2.275 & 2.404 & 2.774 & 2.944 & 3.680 & 4.416 \\
\hline 0.90 & 6 & 1.890 & 2.077 & 2.190 & 2.380 & 2.534 & 2.717 & 3.397 & 4.076 \\
\hline 0.90 & 7 & 1.824 & 1.968 & 2.009 & 2.188 & 2.354 & 3.138 & 3.183 & 3.819 \\
\hline 0.90 & 8 & 1.772 & 1.884 & 1.972 & 2.038 & 2.531 & 2.949 & 3.014 & 3.616 \\
\hline 0.90 & 9 & 1.706 & 1.816 & 1.942 & 2.057 & 2.391 & 2.797 & 2.877 & 3.452 \\
\hline 0.90 & 10 & 1.674 & 1.761 & 1.833 & 1.947 & 2.276 & 2.671 & 2.763 & 3.315 \\
\hline 0.95 & 0 & 7.393 & 10.003 & 11.430 & 14.285 & 16.013 & 21.349 & 26.691 & 32.026 \\
\hline 0.95 & 1 & 4.143 & 4.632 & 5.192 & 6.489 & 7.247 & 9.662 & 12.080 & 14.494 \\
\hline 0.95 & 2 & 3.270 & 3.631 & 4.283 & 4.517 & 5.150 & 6.866 & 8.584 & 10.299 \\
\hline 0.95 & 3 & 2.735 & 3.173 & 3.412 & 3.625 & 4.210 & 5.612 & 7.016 & 8.419 \\
\hline 0.95 & 4 & 2.530 & 2.689 & 2.908 & 3.111 & 3.668 & 4.890 & 6.114 & 7.336 \\
\hline 0.95 & 5 & 2.309 & 2.558 & 2.886 & 3.221 & 3.312 & 4.415 & 5.520 & 6.623 \\
\hline 0.95 & 6 & 2.152 & 2.307 & 2.613 & 2.927 & 3.801 & 4.075 & 5.095 & 6.113 \\
\hline 0.95 & 7 & 2.034 & 2.258 & 2.408 & 2.705 & 3.530 & 3.818 & 4.774 & 5.728 \\
\hline 0.95 & 8 & 2.000 & 2.097 & 2.247 & 2.532 & 3.318 & 3.616 & 4.520 & 5.424 \\
\hline 0.95 & 9 & 1.921 & 2.078 & 2.300 & 2.392 & 3.147 & 3.451 & 4.315 & 5.177 \\
\hline 0.95 & 10 & 1.856 & 1.963 & 2.180 & 2.276 & 3.005 & 3.314 & 4.144 & 4.972 \\
\hline
\end{tabular}




\section{AL-OMARI ET AL}

Table 3 (continued).

\begin{tabular}{rrrrrrrrrr} 
& \multicolumn{10}{c}{$\boldsymbol{t} / \boldsymbol{\mu}_{\mathbf{0}}$} \\
\cline { 3 - 10 } $\boldsymbol{P}^{*}$ & $\mathbf{0 . 6 2 8}$ & $\mathbf{0 . 9 4 2}$ & $\mathbf{1 . 2 5 7}$ & $\mathbf{1 . 5 7 1}$ & $\mathbf{2 . 3 5 6}$ & $\mathbf{3 . 1 4 1}$ & $\mathbf{3 . 9 2 7}$ & $\mathbf{4 . 7 1 2}$ \\
\hline 0.99 & 0 & 9.857 & 13.337 & 15.240 & 19.047 & 21.351 & 28.465 & 35.588 & 42.702 \\
0.99 & 1 & 5.524 & 6.176 & 6.923 & 8.652 & 9.663 & 12.882 & 16.106 & 19.325 \\
0.99 & 2 & 4.114 & 4.841 & 5.710 & 6.023 & 6.866 & 9.154 & 11.445 & 13.732 \\
0.99 & 3 & 3.463 & 3.845 & 4.549 & 4.833 & 5.613 & 7.483 & 9.355 & 11.225 \\
0.99 & 4 & 3.086 & 3.266 & 3.878 & 4.148 & 4.891 & 6.520 & 8.152 & 9.781 \\
0.99 & 5 & 2.710 & 3.159 & 3.437 & 3.699 & 4.416 & 5.887 & 7.360 & 8.831 \\
0.99 & 6 & 2.554 & 2.854 & 3.122 & 3.379 & 4.076 & 5.434 & 6.793 & 8.151 \\
0.99 & 7 & 2.437 & 2.624 & 2.886 & 3.139 & 3.819 & 5.091 & 6.365 & 7.637 \\
0.99 & 8 & 2.346 & 2.626 & 2.701 & 2.950 & 3.616 & 4.821 & 6.027 & 7.232 \\
0.99 & 9 & 2.195 & 2.467 & 2.823 & 3.189 & 3.452 & 4.601 & 5.753 & 6.903 \\
0.99 & 10 & 2.143 & 2.334 & 2.680 & 3.035 & 3.315 & 4.419 & 5.525 & 6.629 \\
\hline
\end{tabular}

\section{Conclusions}

An acceptance sampling plan was developed for when the life test is truncated at a pre-determined time and the life time of the test follow a three-parameter Lindley distribution. Based on the same conditions, in order to assert a specified mean life with a given confidence level, the three-parameter Lindley distribution results in smaller sample sizes than some other distributions used in acceptance sampling in general. However, the researchers can use the suggested sampling plans easily.

\section{References}

Abd El-Monsef, M. M. E. (2016). A new Lindley distribution with location parameter. Communication in Statistics - Theory and Methods, 45(17), 52045219. doi: 10.1080/03610926.2014.941496

Al-Nasser, A. D., \& Al-Omari, A. I. (2013). Acceptance sampling plan based on truncated life tests for exponentiated Fréchet distribution. Journal of Statistics and Management Systems, 16(1), 13-24. doi:

10.1080/09720510.2013.777571

Al-Omari, A. I. (2014). Acceptance sampling plan based on truncated life tests for three parameter kappa distribution. Stochastics and Quality Control, 29(1), 53-62. doi: 10.1515/eqc-2014-0006

Al-Omari, A. I. (2015). Time truncated acceptance sampling plans for generalized inverted exponential distribution. Electronic Journal of Applied Statistical Analysis, 8(1), 1-12. doi: 10.1285/i20705948v8n1p1 


\section{THREE-PARAMETER LINDLEY DISTRIBUTION IN ASP}

Al-Omari, A. I. (2016). Time truncated acceptance sampling plans for generalized inverse Weibull distribution. Journal of Statistics and Management Systems, 19(1), 1-19. doi: 10.1080/09720510.2013.867703

Al-Omari, A. I., Al-Nasser, A. D., Gogah, F., \& Haq, M. A. (2017). On the exponentiated generalized inverse Rayleigh distribution based on truncated life tests in a double acceptance sampling plan. Stochastics and Quality Control, 32(1), 37-47. doi: 10.1515/eqc-2017-0007

Al-Omari, A. I., \& Zamanzade, E. (2017). Double acceptance sampling plan for time truncated life tests based on transmuted generalized inverse Weibull distribution. Journal of Statistics Applications \& Probability, 6(1), 1-6. doi: 10.18576/jsap/060101

Aslam, M., Jun, C.-H., Lee, H, Ahmad, M., \& Rasool, M. (2011). Improved group sampling plans based on truncated life tests. The Chilean Journal of Statistics, 2(1), 85-97. Retrieved from http://www.soche.cl/chjs/volumes/02/01/Aslam_etal(2011).pdf

Aslam, M., Kundu, D., \& Ahmad, M. (2007). Time truncated acceptance sampling plans for generalized exponential distribution. Journal of Applied Statistics, 37(4), 555-556. doi: 10.1080/02664760902769787

Baklizi, A., \& El Masri, A. E. Q. (2004). Acceptance sampling based on truncated life tests in the Birnbaum Saunders model. Risk Analysis, 24(6), 14531457. doi: 10.1111/j.0272-4332.2004.00541.x

Ghitany, M. E., Atieh, B., \& Nadarajah, S. (2008) Lindley distribution and its application. Mathematics and Computers in Simulation, 78(4), 493-506. doi: 10.1016/j.matcom.2007.06.007

Gui, W., \& Aslam, M. (2017). Acceptance sampling plans based on truncated life tests for weighted exponential distribution. Communications in Statistics - Simulation and Computation, 46(3), 2138-2151. doi:

10.1080/03610918.2015.1037593

Gupta, S. S., \& Groll, P. A. (1961). Gamma distribution in acceptance sampling based on life tests. Journal of the American Statistical Association, 56(296), 942-970. doi: 10.1080/01621459.1961.10482137

Kantam, R. R. L., Rosaiah, K., \& Rao, G. S. (2001). Acceptance sampling based on life tests: Log-logistic model. Journal of Applied Statistics, 28(1), 121 128. doi: 10.1080/02664760120011644 


\section{AL-OMARI ET AL}

Lindley, D. V. (1958). Fiducial distributions and Bayes' theorem. Journal of the Royal Statistical Society: Series B (Methodological), 20(1), 102-107. doi: 10.1111/j.2517-6161.1958.tb00278.x

Malathi, D., \& Muthulakshmi, S. (2017). Economic design of acceptance sampling plans for truncated life test using Frechet distribution. Journal of Applied Statistics, 44(2), 376-384. doi: 10.1080/02664763.2016.1169260

Nehzad, M. S. F., \& Seifi, S. (2017). Repetitive group sampling plan based on the process capability index for the lot acceptance problem. Journal of Statistical Computation and Simulation, 87(1), 29-41. doi:

10.1080/00949655.2016.1189553

Shanker, R., Fesshaye, H., \& Sharma, S. (2016). On quasi Lindley distribution and its applications to model lifetime data. International Journal of Statistical Distributions and Applications, 2(1), 1-7. doi:

10.11648/j.ijsd.20160201.11

Shanker, R., Kumar, K., Shanker, R., \& Leonida, T. (2017). A threeparameter Lindley distribution. American Journal of Mathematics and Statistics, 7(1), 15-26. Retrieved from http://article.sapub.org/10.5923.j.ajms.20170701.03.html

Shanker, R., \& Mishra, A. (2013). A two-parameter Lindley distribution. Statistics in Transition - New Series, 14(1), 45-56.

Tsai, T., \& Wu, S. (2006). Acceptance sampling based on truncated life tests for generalized Rayleigh distribution. Journal of Applied Statistics, 33(6), 595600. doi: 10.1080/02664760600679700 